\title{
Protective Role of Pomegranate on Fatty Liver in Obesity: An Experimental Chemical \& Histopathological Study
}

\author{
Ahmed Hassan El-Rashedy ${ }^{1}$ - Saeed Kamel Belal'2 - Hossam El-Din Osman³ - Gaber \\ Mohamed Shehab ${ }^{4}$ \\ Departments of Pathology ${ }^{1}$, Anatomy ${ }^{2 \& 3}$, and Biochemistry ${ }^{4}$,College of Medicine \& \\ Medical Sciences, Taif University.
}

\begin{abstract}
Aim of the work: Fatty liver is the most common cause of abnormal liver function tests. Since obesity and fatty liver can result in serious drawbacks and represent a considerable incidence rate in Saudi Arabia. This country is a famous one of pomegranate. This study aimed at investigating the ameliorating effects of pomegranate on hepatic lipid accumulation in rats with severe fatty liver in order to provide a cheap natural protective medicine since this health problem can affect the entire world economy.

Material and methods: Twenty-four male Zucker rats aged 13-15 weeks were used. Animals were allowed free access to food and water for 1 week before starting the experiment. According to the body weight (BW), plasma triglycerides (TG) and total cholesterol (TC) levels were measured before treatment. The animals were divided into lean control, lean pomegranate (PGF)-treated, fatty control and fatty PGF- treated groups (six animals per group). Finally, the animals were weighed after a prompt dislocation of their neck vertebra. Then, the liver was rapidly excised, washed with saline on ice and weighed. In addition, one part of it was cut into slices for studies of lipid determination analysis. The right tibia length (TL) was measured for calculation of the ratio of liver weight to TL. A portion of the liver was homogenized and the lipids were extracted with isopropanol. Triglycerides and TC contents in the supernatant were determined.
\end{abstract}

Results: Fatty rats (ZF) had shorten TL but their BWs were increased compared to lean rats. Also, ZF rats showed hepatomegaly reflected by increased liver weight and increased ratio of liver weight to TL. Treatment with PGF extract did not change BW and TL, but it reduced liver weight and the ratio in ZF rats. PGF did not affect these parameters in lean ( ZL) rats. Fatty rats exhibited severe hepatic steatosis, reflected by a marked increase in hepatic TG as well as hepatic TC contents and fatty droplets visualized by either light microscopy as large vacuoles occupying the cytoplasm of hepatocytes pushing their nuclei to the periphery against the cell membrane giving signet-ring appearance or by electron microscopy as membrane-bound inclusions closely near the endoplasmic reticulum with indentation of the nuclei of the affected cells. Interestingly, 6-week treatment of fatty rats with PGF extract reduced hepatic TG contents and fatty droplets whereas it did not alter hepatic TC contents. This treatment showed minimal effects in ZL rats.

Conclusion: These findings are potentially important for supporting the effectiveness of pomegranate in the treatment of obesity - induced fatty liver disease through the improvement of abnormal lipid metabolism.

Key words: Pomegranate - Obesity - Fatty liver - Serum Chemistry - Histopathology.

\section{Introduction}

Obesity is predictive of the presence of fibrosis potentially progressing to advanced liver disease. Non-alcoholic fatty liver disease (NAFLD), hypertriglyceridemia and elevated free fatty acids are present in the majority of patients with metabolic syndrome and type 2 diabetes mellitus and are strongly associated with hepatic insulin resistance (Stefanovic-Racic et al., 2008). 
Non-alcoholic fatty liver disease is a pathological condition of emerging clinical importance occurring in Saudi Arabia, now recognized as the most common cause of abnormal liver function tests. It is characterized by a wide spectrum of liver damage; simple steatosis may progress to advanced fibrosis and to cryptogenic cirrhosis through steatohepatitis and ultimately to hepatocellular carcinoma (Festi et al., 2004).

Although NAFLD is a syndrome with a multifactorial etiology (Chitturi and Farrell, 2001), obesity, type 2 diabetes and hyperlipidemia are the most common associated factors (Festi et al., 2004) both in children and in adults (Xu et al., 2009).

The prevalence of NAFLD in the general population ranges from 13 to $15 \%$ increasing in subjects with diabetes and with severe obesity and has been reported to range from 25 to $75 \%$ or even higher. Prevention and treatment of the disease may protect a large number of individuals at risk of advanced liver disease and improve metabolic syndrome and diabetes. However, no universally effective treatment has been identified for NAFLD and therapeutic strategies are still largely empirical (Chou et al., 2002).

Pomegranate flowers serve as a remedy for diabetes mellitus (Saxena and Vikram, 2004). Modern uses of pomegranate derived products now include treatment of acquired immune deficiency syndrome (AIDS), in addition to use for cosmetic beautification (Kawamada and Shimada, 2002 ; Moayadi, 2004) and enhancement of breast feeding (Curry, 2004), hormone replacement therapy (Lansky, 2000), resolution of allergic symptoms (Watanabe and Hatakoshi, 2002), cardiovascular protection (Shiraishi et al., 2002; Aviram and Dornfeld, 2003), oral hygiene (Kim and Kim, 2002), ophthalmic ointment (Bruijn et al., 2003), weight loss soap (Guojian, 1995), and as an adjunct therapy to increase bioavailability of radioactive dyes during diagnostic imaging (Amorim et al., 2003).

Pomegranate juice (PJ) is rich in antioxidants of the polyphenolic class which includes tannins and anthocyanins. The antioxidant level in PJ was found to be higher than that in other natural juices such as blueberry, cranberry and orange as well as in red wine (Aviram et al.,2002). Antioxidants posses numerous important biological properties including antiinflammatory and anti-aging effects as well as protection against cholesterol oxidation, atherogenesis and Alzheimer's disease (Hartman et al., 2006; Ramassamy, 2006; Ignarro et al.,2007). These antioxidant therapeutic actions are identical to many of the actions of nitric oxide (NO) and in fact protect $\mathrm{NO}$ against oxidative destruction and thereby enhance NO actions (Nigris et al.,2007).

Previous studies established that regular administration of PJ to atherosclerotic animals and humans produced a significant protective effect (Aviram et al., 2000 ; Aviram et al., 2002). In addition, PJ administrated to hypertensive patients caused a significant drop in blood pressure (Aviram and Dornfeld, 2001). Clinically, a widely distributed condition that is called metabolic syndrome includes obesity, hypertension, dyslipidemia and diabetes mellitus (Opie, 2007).

The goal of this study was to investigate the ameliorating effects of pomegranate on hepatic lipid accumulation in rats with severe fatty liver, since obesity with fatty liver can result in serious drawbacks and represent a considerable incidence rate in Saudi Arabia which is a famous country of pomegranate, in order to provide a cheap, safe and natural protective therapy for this health problem that can affect the entire world economy.

\section{Material and methods}

\section{Chemicals and reagents :}

The kits for determination of triglyceride (TG) and total cholesterol (TC) were purchased commercially (Wako, Osaka, Japan). Oleanolic acid, gallic acid and ursolic acid were purchased from Sigma, Guangzhou, China.

\section{Animals and diet :}

Twenty-four of male Zucker rats half of whom weighed $200 \pm 25$ (Lean) \& other half weighed $375 \pm 30 \mathrm{~g}$ (Fatty). The animals were housed in stainless-steel cages under strict hygienic conditions and maintained at standard laboratory 
conditions of temperature, relative humidity and light/dark cycle as well as a standard pelleted diet containing more than $22 \mathrm{~g} / \mathrm{kg}$ crude protein, more than $60 \mathrm{~g} / \mathrm{kg}$ crude fat and less than $40 \mathrm{~g} / \mathrm{kg}$ crude fiber (Y.S.F. Pty., Ltd., Sydney, Australia) and water were provided.

\section{Preparation and identification of the extract}

Dried pomegranate flower (PGF) was extracted as described by Afaq, et al (2005) at room temperature three times with 5 volumes of methanol. The solvent was evaporated under reduced pressure below $50{ }^{\circ} \mathrm{C}$ to give a methanolic extract (yield $40 \%$ ). It has been reported that PGF contains oleanolic acid ( $3 \beta$-hydroxy-olea12-en-28-oic acid), gallic acid (3,4,5trihydroxy-benzoic acid) and ursolic acid (3ß-hydroxy-urs-12-en-28-oic acid) in which oleanolic acid has PPAR- activator gene properties (Li et al., 2007) or hepatoprotective effects (Liu, 2005).

\section{Experimental Design:}

Fatty animals were allowed free access to food and water for 1 week before starting the experiment. The animals were divided into four groups, each group involved 6 animals; first (Lean) \& third (fatty) groups, taken as controls, being received no medication but were taken standard diet. The second (Lean) $\&$ fourth (fatty) groups were received (through a gastric tube) $500 \mathrm{mg} / \mathrm{kg}$ of pomegranate based on the experience that this dosage showed maximal effect in rats (Li et al., 2005). The PGF extract was given orally by gavage once daily for 6 weeks. At the endpoint of the experiment, animals were euthanized by prompt dislocation of the neck vertebra under halothane anesthesia, and then weighed. The liver was rapidly excised, weighed and prepared for the histopathological staining. Also, the right tibia length (TL) was measured and triglycerides (TG) and TC contents were determined in the supernatant.

\section{Extract administration and measurement} of body weight (BW), liver weight, hepatic triglycerides $(T G)$ and total cholesterol (TC) contents in rats:

According to the BW, plasma TG \& TC levels were measured before treatment, rats were divided into lean control (LC), lean received PGF (LP), fatty control (FC) and fatty group treated with PGF (FG) (six animals per group). We chose $500 \mathrm{mg} / \mathrm{kg}$ of pomegranate based on the experience mentioned by Li et al. (2005) that this dosage showed a maximal effect in rats. The PGF extract (suspended in 5\% acacia) or vehicle control was given orally by gavage once daily for 6 weeks. At endpoint of the experiment, animals were euthanized by prompt dislocation of the neck vertebra under halothane anesthesia, and then weighed. The liver was rapidly excised and washed with saline on ice. After excess water on the surface was removed with filter paper, the livers were weighed. One part of the liver was cut into slices, frozen in liquid nitrogen and stored at $-80{ }^{\circ} \mathrm{C}$ for studies of lipid determination analysis. The right tibia length (TL) was measured for calculation of the ratio of liver weight to TL (Xu et al.,2009). A portion of the liver was homogenized and the lipids were extracted with isopropanol $(1 \mathrm{ml} / 50 \mathrm{mg})$ ( $\mathbf{L i}$ et al., 2008). Triglycerides and TC contents in the supernatant were determined by enzymatic colorimetric methods with commercial kits (Wako, Osaka, Japan). The hepatic TG and TC contents are expressed both as $\mathrm{mg} / \mathrm{g}$ liver tissue and as total amount per liver (g/liver).

\section{Hepatohistological examination}

After the animals were sacrificed, small parts of the liver were fixed in $10 \%$ formalin, washed in tap water, dehydrated, cleared and embedded in paraffin. Sections were cut and stained with hematoxylin and eosin for assessment the cases.

\section{Ultrastructural Studies:}

Semithin and Ultrathin sections were cut and stained with uranyl acetate and lead citrate. The ultrastructure of the tissues was examined under transmission electron microscope.

\section{Data analysis}

All results are expressed as means \pm SEM. Data were analyzed by 1 -factor analysis of variance (ANOVA). If a statistically significant effect was found, NewmanKeuls test was performed to isolate the difference between the groups. $P$ values less than $0.05(P<0.05)$ were considered as indicative of significance. 


\section{Results}

Zucker fatty (ZF) whether control (CF) or pomegranate-treated $(\mathrm{PF})$ rats had shorten TL (Fig.II), but their BWs were increased (Fig.I), compared to Zucker lean (ZL) whether control (CL) or pomegranatereceived (PL) rats. ZF rats showed hepatomegaly, reflected by increased liver weight (Fig.III) and ratio of liver weight to TL (Fig.IV). Treatment with PGF extract did not change BW and TL, but it reduced liver weight and the ratio in ZF rats (Figs. I - IV). PGF did not affect these parameters in ZL rats (Figs. I - IV). ZF rats exhibited severe hepatic steatosis, reflected by a marked increase in hepatic TG contents (Figs.V\&VI) and fatty droplets visualized
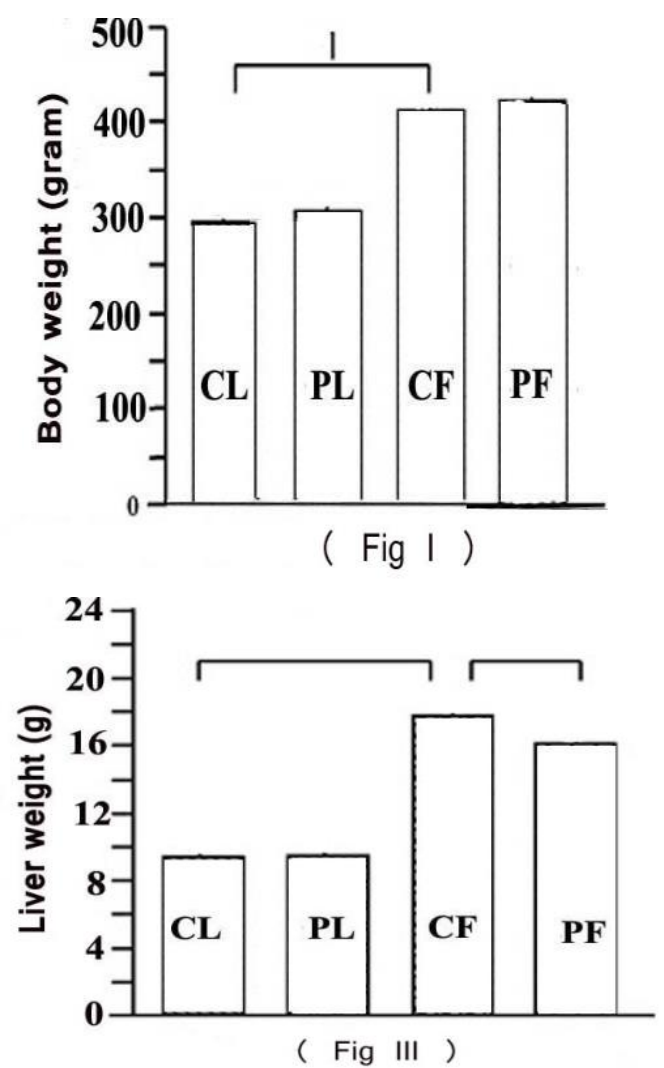

by light microscopy to be large vacuoles occupying the cytoplasm of hepatocytes pushing their nuclei to the periphery against the cell membrane giving signet-ring appearance (Fig. IX) and ultrastructurally as membrane-bound inclusions closely near the endoplasmic reticulum with indentation of the nucleus of the affected cells (Fig. $\mathbf{X}$ ). In addition, there was an increased hepatic TC content (Fig. VIII). Interestingly, ZF rats treated with PGF extract showed reduced hepatic TG contents and fatty droplets (Figs. V, IV \& X) whereas it did not reveal significantly altered hepatic TC contents (Figs. VII \& VIII) . This treatment showed minimal effects in ZL rats (Figs. $\mathbf{V}$ - VIII).
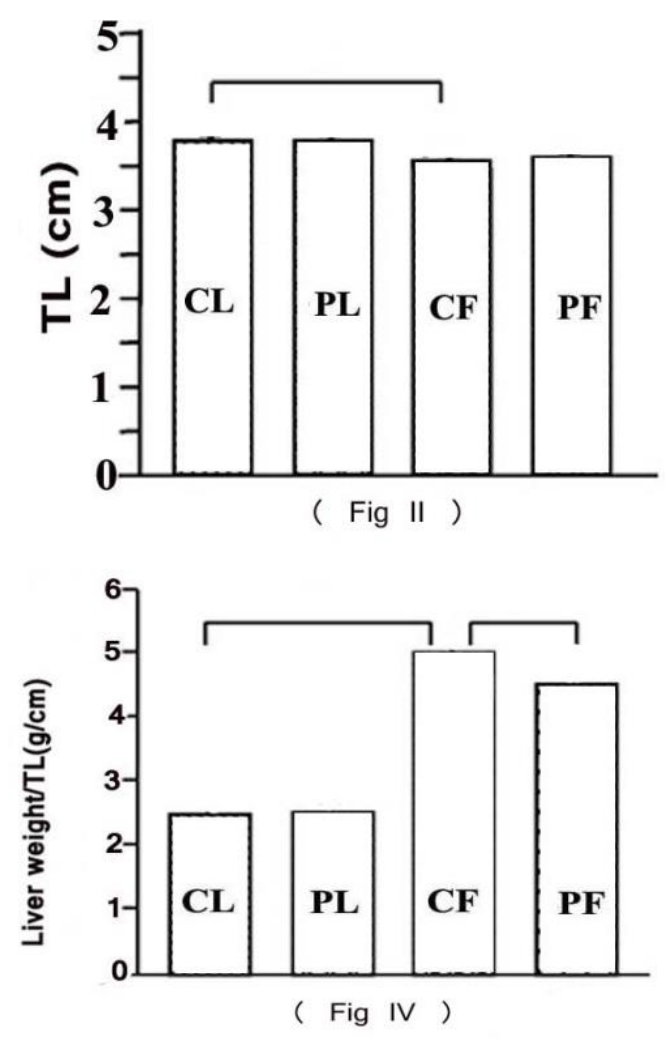

Figs. I-IV: Effects of methanolic extract of pomegranate flower (PGF) on body weight (Fig. I) tibia length (TL; Fig. II), liver weight (Fig. III) and the ratio of liver weight to TL ( Fig. IV) in control lean (CL), pomegranate treated lean (PL), control fatty (CF) and pomegranate treated fatty $(\mathrm{PF})$ rats. The ratio of liver weight to TL was calculated. All values are means \pm SEM $(n=$ 6). $* P<0.05$. Con: control. 

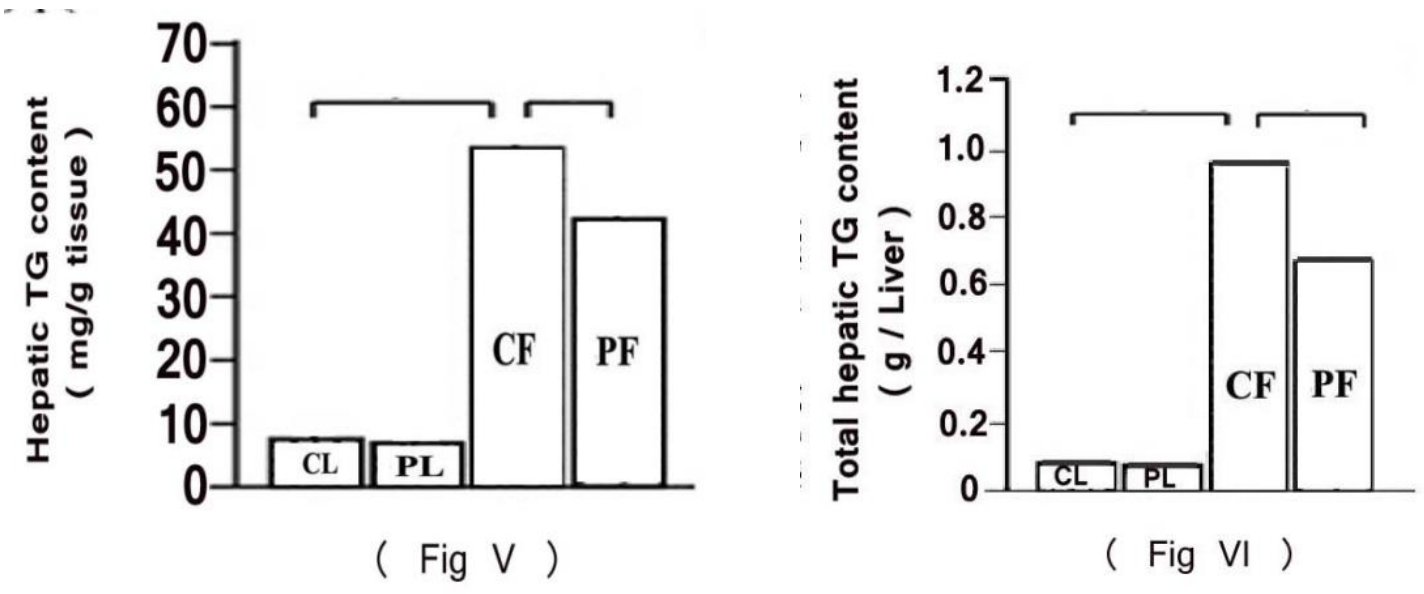

Figs. V-VI : Effects of PGF extract on relative (Fig. V) and total (Fig. VI) hepatic triglyceride (TG) contents in the livers of CL \& PL as well as CF \& PF rats. Note: all values are means $\pm \operatorname{SEM}(n=6) . * P<0.05$.
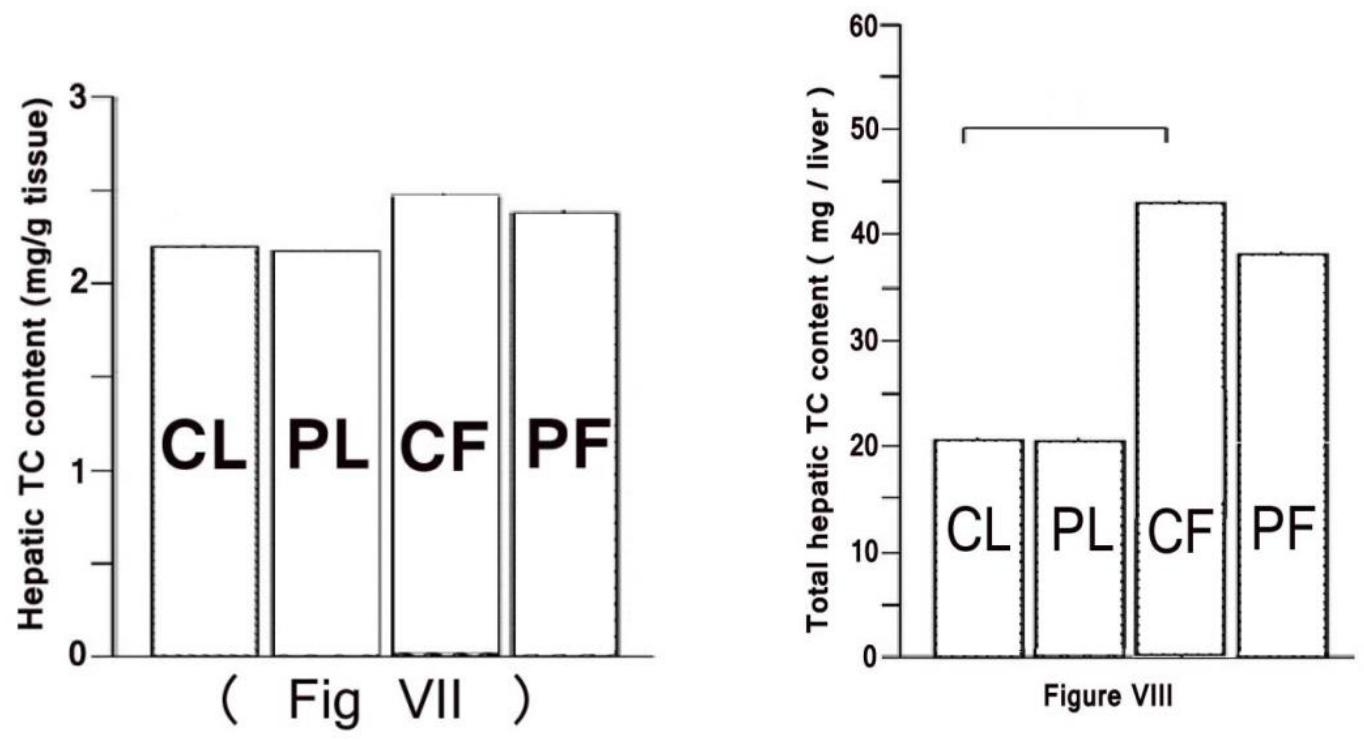

Figs. VII \&VIII: Effects of PGF extract on relative (Fig.VII) and total (Fig. VIII) hepatic total cholesterol (TC) contents in the livers of CL and PL as well as CF and PF rats. All values are means $\pm \operatorname{SEM}(n=6) . * P<0.05$. 

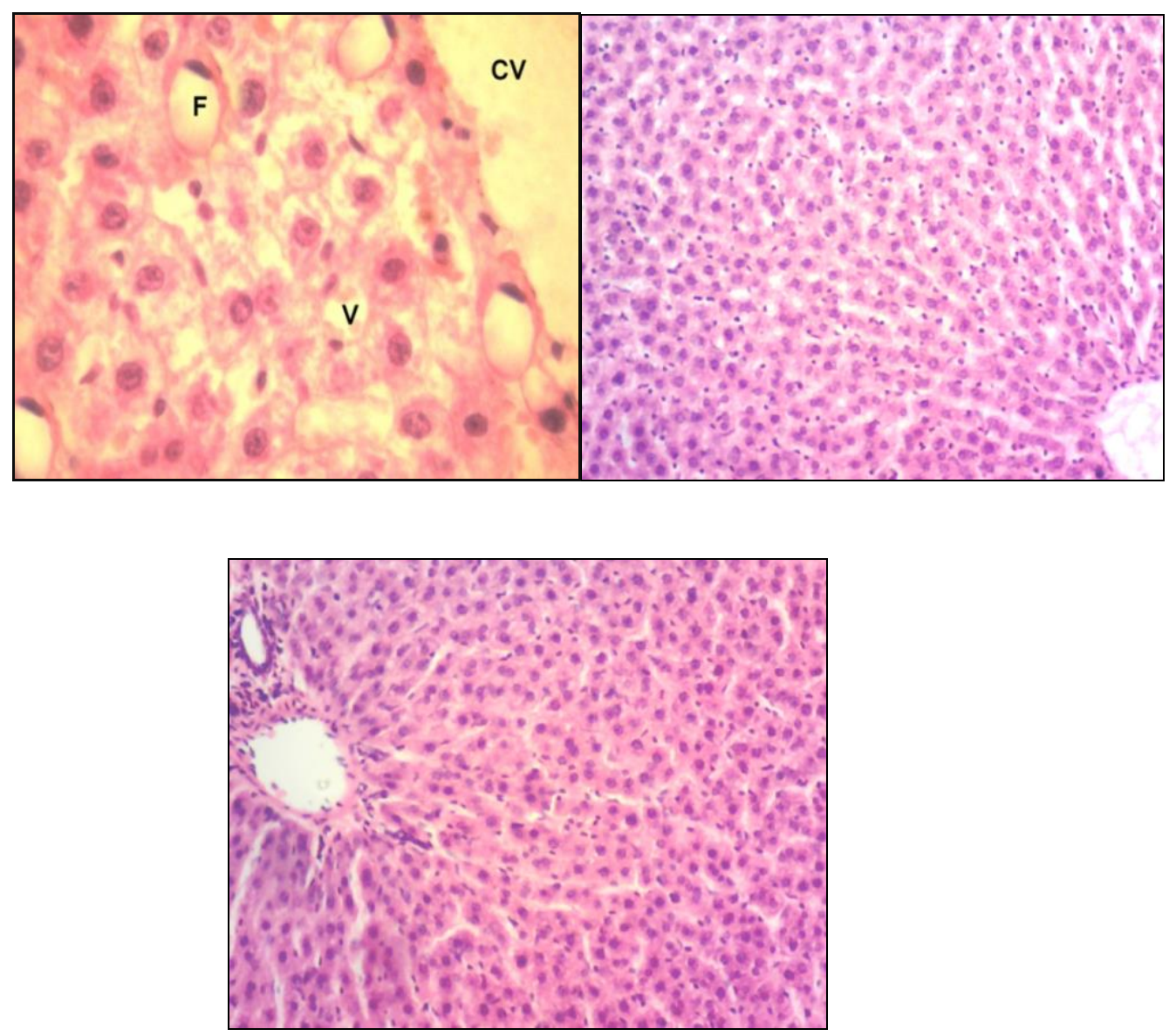

Fig.IX: Photomicrographs of hepatic tissue of ZL (group 1; upper left ; Hx.\& E. x100) showing no intrahepatocytic fatty accumulation, that of ZF ( group 3; upper right; Hx.\& E. x200 ) with signet - ring appearance $(\mathrm{F})$ denoting intracellular accumulation of fatty vacuoles $(\mathrm{V})$ and that of ZF (group 4) treated with PGF extract (lower middle; Hx.\& E. x100) displaying disappearance of intrahepatocytic fatty accumulation. 

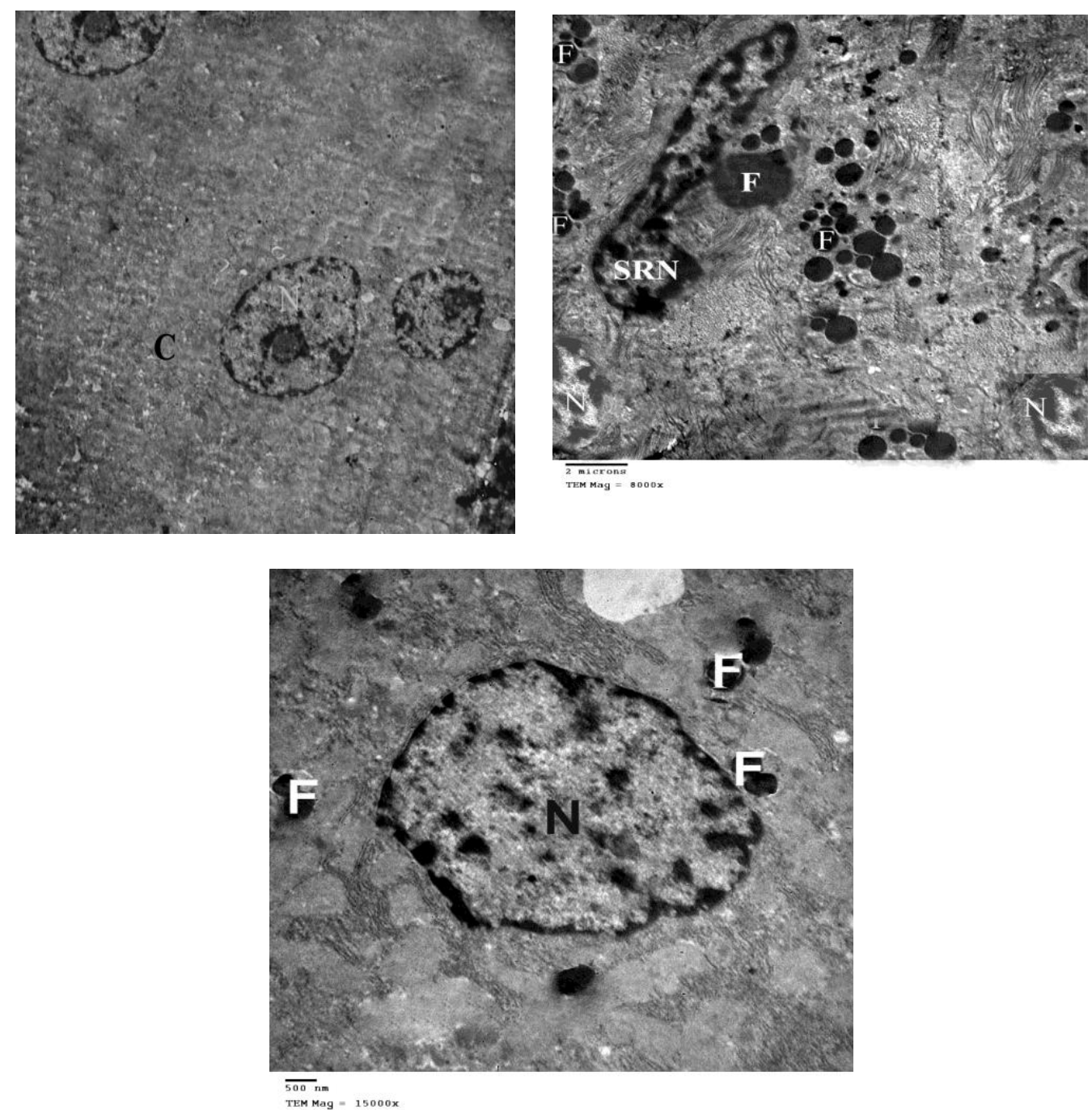

Fig. X: Electromicrographs of hepatic tissue of ZL ( group 1; upper left ) showing no fatty accumulation within the cytoplasm (C) with oval or round nuclei, that of ZF ( group 3; upper right) with indentation of the nucleus (SRN) by variable sized fat globules (F) near the endoplasmic reticulum and that of ZF treated with PGF extract (group 4 ; lower middle ) displaying a decrease in the amount of fat globules $(\mathrm{F})$ and the nucleus restored its normal shape $(\mathrm{N})$. (Electron micrographs $\mathrm{x} 8000)$.

\section{Discussion}

In the present study, we demonstrated that fatty rats (ZF) had shorten TL but their BWs were increased compared to lean rats. Also, ZF rats showed hepatomegaly reflected by increased liver weight and increased ratio of liver weight to TL. Treatment with PGF extract did not change $\mathrm{BW}$ and TL, but it reduced liver weight and the ratio in ZF rats. PGF did not affect these parameters in lean ( $\mathrm{ZL}$ ) rats. Fatty rats exhibited severe hepatic steatosis, reflected by a marked increase in hepatic TG as well as hepatic TC contents and fatty droplets visualized by either light or electron microscopy. Interestingly, 6-weeks treatment of fatty rats with PGF extract reduced hepatic TG contents and fatty droplets whereas it did not alter hepatic TC contents. This treatment showed minimal effects in ZL rats. These findings are consistent with those of Xu et al. (2009). A number of studies in insulin-resistant animal models have shown marked 
decreases in the liver triglycerides content and adiposity by PPAR - $\alpha$ gene agonists (Guerre-Millo et al., 2000). PPAR- $\alpha$ agonist, normalized fatty livers in fat-fed rats (Ye et al., 2003) and markedly improved ethanol-induced hepatic steatosis and TG accumulation in the liver of rats (Fischer et al., 2003). In Tokushima fatty rats, fenofibrate (a well characterized PPAR- $\alpha$ agonist) markedly reduced hepatic TG content which was accompanied by a decrease in plasma TG levels (Lee $\boldsymbol{e t}$ al., 2004). Huang et al.(2005a) stated that the PGF and one of its components; oleanolic acid have been demonstrated to be specifically enhanced PPAR- $\alpha$ luciferase reporter gene activity in HEK 293 cells. In addition, the treatment with PGF diminished cardiac triglyceride accumulation accompanied by downregulation of the overexpressed cardiac PPAR- $\alpha$, CPT- 1 and ACO mRNAs in the hearts of Zucker diabetic fatty rats. These effects may have resulted from reduced circulating lipid levels. Moreover, Xu et al. (2009) found that PGF therapy enhanced the hepatic mRNA expression of PPAR- $\alpha, \mathrm{CPT}-1$ and ACO as well as SCD-1 genes in ZF rats and they discovered that PGF enhanced endogenous expression of PPAR- $\alpha$ and ACO mRNAs in the liver-derived HepG2 cell line. Thus, these results suggest that PGF extract ameliorates hepatic steatosis in $\mathrm{ZF}$ rats, at least partly by activating PPAR$\alpha-$ and SCD-1-mediated hepatic expression of genes responsible for fatty acid oxidation. It would be interesting to investigate why PGF treatment enhanced hepatic expression of these genes, but did not alter the lipid contents in the livers of normal Zucker lean (ZL) rats.

Fatty acid uptake and synthesis as well as triglycerides hydrolysis affect triglyceride deposition in liver. PPAR- $\gamma$ may stimulate hepatic gene expression involved in fatty acid uptake, storage and synthesis (Loviscach et al., 2000). However, expression of PPAR- $\gamma$ in liver is low (Chou et al., 2002). Another factor playing in lipogenesis in liver is SREBP-1 which activates most genes required for de novo synthesis of fatty acid and triglyceride synthesis (Horton et al., 2002). PGF extract has been demonstrated together with one of its components; gallic acid to enhance
PPAR- $\gamma$ protein and mRNA expression in human THP-1 differentiated macrophage cells (Huang et al., 2005 b). However, Xu et al. (2009) displayed no significant change in hepatic expression of PPAR- $\gamma$ mediated genes encoding PPAR- $r$, FAS and ACC. Moreover, they also found that FATP, LpL and SREBP- 1 mRNAs were not altered in $\mathrm{ZF}$ rats compared to ZL rats. Thus, no evidence was obtained for the effects of PGF extract on expression of genes that mediate fatty acid uptake and synthesis and triglyceride hydrolysis.

Interestingly, Kaur et al. (2006) reported that chronic administration of PGF did not increase, but rather decreased, liver weight in $\mathrm{ZF}$ rats whilst having no effect on liver weight in ZL rats. They also stated that an ethanolic extract of PGF containing a large amount of polyphenols possesses potent anti-oxidant activity and hepatoprotective property in vitro and in vivo. Oleanolic acid and ursolic acid found in PGF extract are well known for their hepatoprotective effects in both acute chemical-induced liver injury and chronic liver fibrosis and cirrhosis due to their anti-oxidant and antiinflammatory actions (Liu, 2005). Therefore, another investigation is needed to detect weather the anti-oxidant and antiinflammatory properties of pomegranate are associated with the decrease of the liver weight in ZF rats.

In conclusion, our findings suggest that PGF extract ameliorates fatty liver in the obese rats. The herb-elicited upregulation of hepatic expression of genes responsible for fatty acid oxidation may possibly result in a decrease in lipid accumulation in the liver. Therefore, the present study is potentially important for supporting the extension of these findings to clinical trials in order to demonstrate the effectiveness of pomegranate in the prevention and/or treatment of obesity- induced non-alcoholic fatty liver disease, through modulation of abnormal lipid metabolism.

\section{Recommendation}

Further studies are needed to elucidate the detailed mechanism of action of pomegranate constituents in all its 
preparations in vivo particularly with regard to their metabolic effects.

\section{References}

Afaq F., Saleem M., Krueger C.G., Reed J.D., Mukhtar H. (2005): Anthocyanin- and hydrolyzable tannin-rich pomegranate fruit extract modulates MAPK and NFkappaB pathways and inhibits skin tumorigenesis in CD1 mice. Int. J. Cancer ; 113: 423-33.

Amorim LF, Catanho MT, Terra DA, Brandao KC, Holanda CM, Jales-Junior LH, Brito LM, Gomes ML, De Melo VG, Bernardo-Filho M, Cavalcanti Jales RL (2003): Assessment of the effect of Punica granatum (pomegranate) on the bioavailability of the radiopharmaceutical sodium pertechnetate $(99 \mathrm{mTc})$ in wistar rats. Cellular and Molecular Biology; 49: 501-7.

Aviram $M$ and Dornfeld $L$ (2001): Pomegranate juice consumption inhibits serum angiotensin converting enzyme activity and reduces systolic blood pressure. Atherosclerosis; 158:195-8.

Aviram M and Dornfeld L (2003): Methods of using pomegranate extracts for causing regression in lesions due to arteriosclerosis in humans. US Patent: 6641850.

Aviram ML, Dornfeld M, Rosenblat N, Volkova M, Kaplan R, Coleman T, Hayek D (2000): Pomegranate juice consumption reduces oxidative stress, atherogenic modifications to LDL and platelet aggregation: studies in humans and in atherosclerotic apolipoprotein E-deficient mice. American J. of Clinical Nutrition; 71: 1062-76.

Aviram M, Dornfeld L, Kaplan M, Coleman R, Gaitini D, Nitecki S, Hofman A, Rosenblat M, Volkova N, Presser D, Attias J, Hayek T, Fuhrman B (2002): Pomegranate juice flavonoids inhibit lowdensity lipoprotein oxidation and cardiovascular diseases: studies in atherosclerotic mice and in humans. Drugs under Experimental and Clinical Research ; 28: 49-62.

Bruijn CD, Christ FR, Dziabo AJ (2003): Ophthalmic, pharmaceutical and other healthcare preparations with naturally occurring plant compounds, extracts and derivatives. US Patent Application 20030086986.

Chitturi S and Farrell GC (2001): Etiopathogenesis of nonalcoholic steatohepatitis. Seminars in Liver Disease; 21: 27-41. Chou CJ, Haluzik M, Gregory C, Dietz KR, Vinson C, Gavrilova O, Reitman ML (2002): WY14,643, a peroxisome proliferator-activated receptor alpha (PPARalpha) agonist, improves hepatic and muscle steatosis and reverses insulin resistance in lipoatrophic A-ZIP/F-1 mice. $J$. Biolog. Chem.; 277: 24484-9.

Curry SC (2004): Breast enhancement system. U.S. Patent: 6673366.

Festi D, Colecchia A, Sacco T, Bondi M, Roda E, Marchesini G (2004): Hepatic steatosis in obese patients: clinical aspects and prognostic significance. Obesity Reviews; 5: 27-42.

Fischer M, You M, Matsumoto M, Crabb DW (2003): Peroxisome proliferator activated receptor alpha (PPAR alpha) agonist treatment reverses PPARalpha dysfunction and abnormalities in hepatic lipid metabolism in ethanol-fed mice. J. Biol. Chem.; 278: $27997-$ 28004.

Guerre-Millo M, Gervois P, Raspe E, Madsen L, Poulain P, Derudas B, Herbert JM, Winegar DA, Willson TM, Fruchart JC, Berge RK, Staels B (2000): Peroxisome proliferator-activated receptor alpha activators improve insulin sensitivity and reduce adiposity. J. Biol. Chem.; 275:16638-42.

Guojian L (1995): Body weight-reducing soaps containing algae and plant extracts. Chinese Patent CN 1104246.

Hartman RE, Shah A, Fagan AM, Schwetye KE (2006): Pomegranate juice decreases amyloid load and improves behavior in a mouse model of Alzheimer's disease. Neurobiol.Dis.;24:506-15.

Horton JD, Goldstein JL, Brown MS (2002): SREBPs: activators of the complete program of cholesterol and fatty acid synthesis in the liver. J. Clin. Invest.; 109:1125-31.

Huang TH, Peng G, Kota BP, Li GQ, Yamahara J, Roufogalis BD, Li Y (2005a): Pomegranate flower improves cardiac lipid metabolism in a diabetic rat model: role of lowering circulating lipids. $B r . \quad J$. Pharmacol.;145;767- 74 .

Huang TH, Peng G, Kota BP, Li GQ, Yamahara J, Roufogalis BD, Li Y (2005b): Anti-diabetic action of Punica granatum flower extract: activation of PPARgamma and identification of an active component. Toxicology and Applied Pharmacology;207:160-9.

Ignarro LJ, Balestrieri ML, Napoli C (2007): Nutrition, physical activity and cardiovascular disease: an update. Cardiovasc. Res.;73:326-40.

Kaur G, Jabbar Z, Athar M, Alam MS (2006): Punica granatum (pomegranate) flower extract possesses potent antioxidant activity and abrogates Fe-NTA induced hepatotoxicity in mice. Food and Chemical Toxicology;44:98493.

Kawamada $Y$ and Shimada $T$ (2002): Cosmetic or topical compositions containing 
Punica granatum extracts. Japan Kokai Tokkyo Koho, Japanese Patent : JP 2002234814 A2 20020823.

Kim MM and Kim S (2002): Composition for improving oral hygiene containing Punica granatum L. extract. Korean Patent: KR 2002066042.

Lansky EP (2000): Pomegranate supplements prepared from pomegranate material including pomegranate seeds. US Patent: 6060063.

Lee GY, Kim NH, Zhao ZS, Cha BS, Kim YS (2004): Peroxisome proliferator activated receptor alpha activates transcription of the rat hepatic malonyl-CoA decarboxylase gene: a key regulation of malonyl-CoA level. Biochem. J.;378:983-990.

Li Y, Wen S, Kota B, Peng G, Li GQ, Yamahara J, Roufogalis BD (2005): Punica granatum flower extract, a potent alphaglucosidase inhibitor, improves postprandial hyperglycemia in Zucker diabetic fatty rats. $J$. Ethnopharmacology; 99: 239-44.

Li Y, Qi Y, Huang TH, Yamahara J, Roufogalis BD (2007): Pomegranate flower: a unique traditional antidiabeteic medicine with dual PPAR- $\alpha / \gamma$ activator properties. Diabetes, Obesity and Metabolism; 10:1326-1463.

Li Y, Qi Y, Kim MS, Xu KZ, Huang TH, Rong X, Murray M, Yamahara J (2008): Increased renal collagen cross-linking and lipid accumulation in nephropathy of Zucker diabetic fatty rats. Diabetes/Metabolism Research and Reviews; 24: 498-506.

Liu J (2005): Oleanolic acid and ursolic acid: research perspectives. J. Ethnopharmacology; 100: 92-4.

Loviscach M, Rehman N, Carter L, Mudaliar S, Mohadeen P, Ciaraldi TP, Veepkamp JH, Henry RR (2000): Distribution of peroxisome proliferator-activated receptors (PPARs) in human skeletal muscle and adipose tissue: relation to insulin action. Diabetologia;43:30411.

Moayadi A (2004): Mixtures of pomegranate seed oils for cosmetics. Japanese Patent : JP 2004083544 A2 20040318.

Nigris F, Ignarro-Williams S, Sica V, Lerman LO (2007): Beneficial effects of a pomegranate fruit extract rich in punicalagin on oxidationsensitive genes and eNOS activity at sites of perturbed shear-stress and atherogenesis. Cardiovasc. Res.;73:414-23.

Opie LH (2007): Metabolic syndrome. Circulation;115:e32-e35.

Ramassamy C (2006): Emerging role of polyphenolic compounds in the treatment of neurodegenerative diseases: a review of their intracellular targets. Eur.J.Pharmacol.; 545:5164.
Saxena A and Vikram NK ( 2004): Role of selected Indian plants in management of type 2 diabetes: a review. Journal of Alternative and Complementary. Medicine; 10: 369-78.

Shiraishi T, Abe M, Miyagawa T (2002): Cheese foods containing conjugated polyunsaturated fatty acid glycerides. Japanese Patent: JP 2002176913.

Stefanovic-Racic M, Perdomo G, Mantell BS, Sipula IJ, Brown NF, O'Doherty RM (2008): A moderate increase in carnitine palmitoyltransferase 1a activity is sufficient to substantially reduce hepatic triglyceride levels. American Journal of Physiology; 294: E969E77.

Watanabe $K$ and Hatakoshi $M$ (2002): Punica granatum leaf extracts for inactivation of allergen. Japan Kokai Tokkyo Koho. Japanese Patent: JP 2002370996 A2 20021224.

Xu KZ, Zhu C, Kim MS, Yamahara J, Li Y (2009): Pomegranate flower ameliorates fatty liver in an animal model of type 2 diabetes and obesity. J. Ethnopharmacology; 123 : 280 -7.

Ye JM, Iglesias MA, Watson DG, Ellis B, Wood L, Jensen PB, Sorensen RV, Larsen PJ, Cooney GJ, Wassermann K, Kraegen EW (2003): PPARalpha/ gamma ragaglitazar eliminates fatty liver and enhances insulin action in fat-fed rats in the absence of hepatomegaly. American J. Physiol.; 284: E531-E540. 


\title{
الدور الوقائي للرمان على الكبد الدهنى فى مرض السمنة: دراسة تجريبية كيميائية نسيجية في في الكية
}

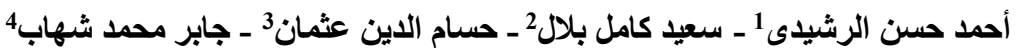

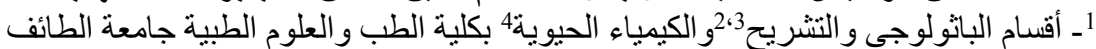

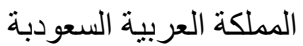

يعتبر الكبد الدهنى من أكثر الأسباب شيو عاً لإضطر ابات وظائف الكبد وحيث أن السمنة والكبد الدهنى

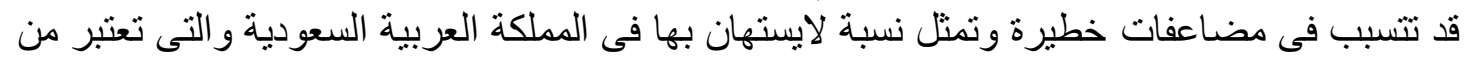

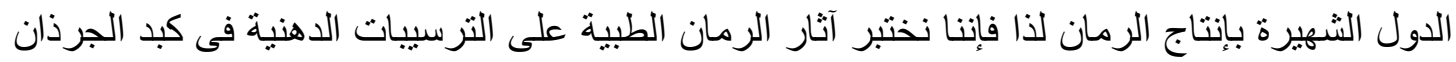

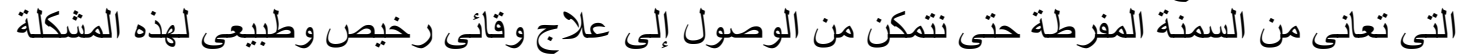

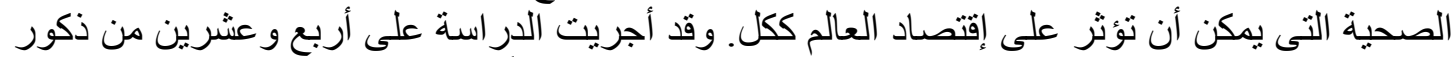

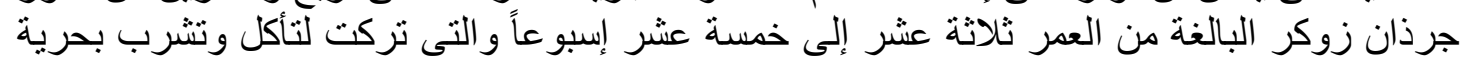

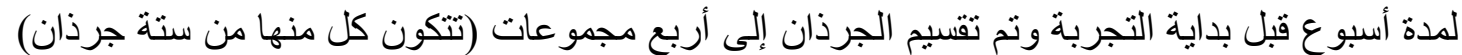

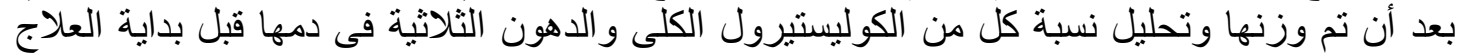

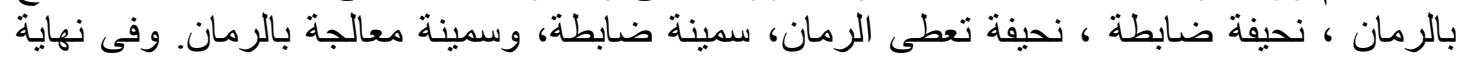

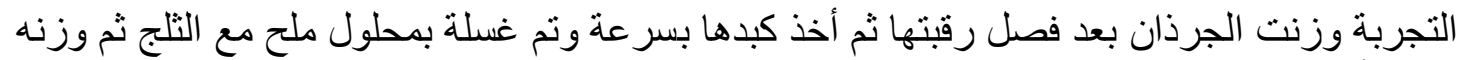

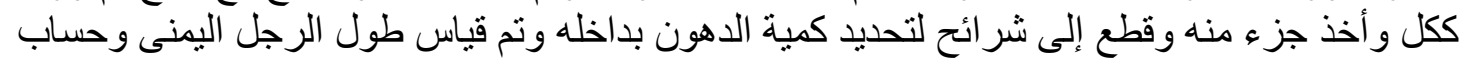

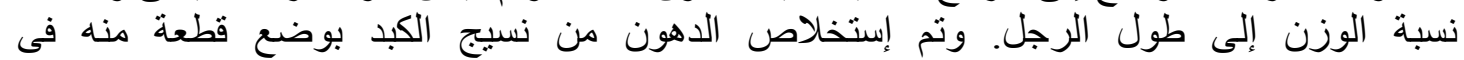

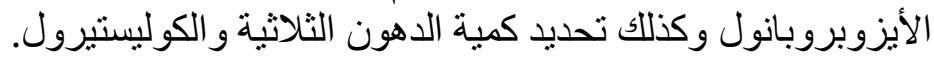

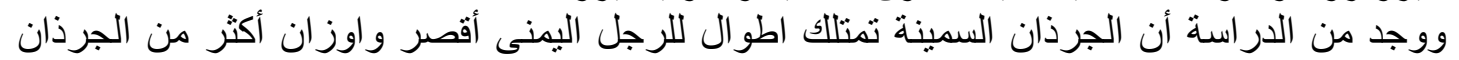

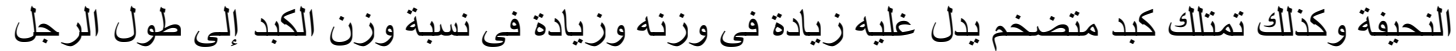

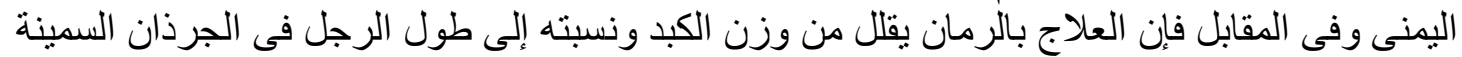

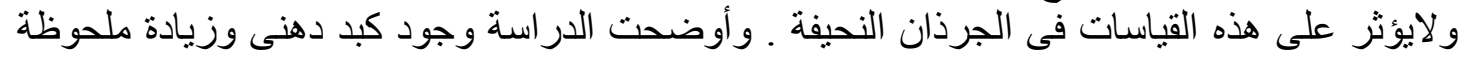

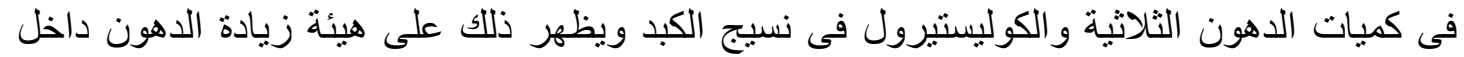

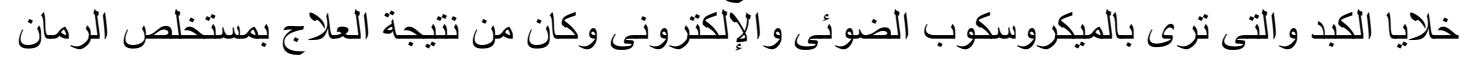

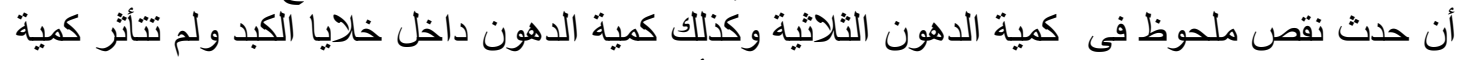

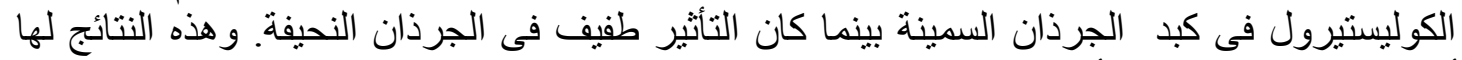
أهميتها القصوى لتدعيم تأثير الرمان فى علاج الكبد الدهنى المصاحب للسمنة عن طريق تحسين عملية أيض الدهون. 